\title{
Lymph node removal enhances corneal graft survival in mice at high risk of rejection
}

\author{
Jarmila Plšková1,2,3, Vladimír Holán², Martin Filipec ${ }^{3}$ and John V Forrester*1
}

Address: ${ }^{1}$ Department of Ophthalmology, University of Aberdeen, Aberdeen, AB25 2ZD, Scotland UK, ${ }^{2}$ Institute of Molecular Genetics, Academy of Sciences, Prague, 166 37, Czech Republic and '3Department of Ophthalmology, Charles University, Prague, 128 08, Czech Republic

Email: Jarmila Plšková - plskovaj@hotmail.com; Vladimír Holá - holan@img.cas.cz; Martin Filipec - martin.filipec@vfn.cz; John V Forrester* - j.forrester@abdn.ac.uk

* Corresponding author

Published: 23 March 2004

BMC Ophthalmology 2004, 4:3
Received: 08 October 2003

Accepted: 23 March 2004

This article is available from: http://www.biomedcentral.com//47I-24/5/4/3

(C) 2004 Plšková et al; licensee BioMed Central Ltd. This is an Open Access article: verbatim copying and redistribution of this article are permitted in all media for any purpose, provided this notice is preserved along with the article's original URL.

\begin{abstract}
Background: As shown previously, the submandibular (SM) lymph node (LN) is required for priming the immune response during corneal graft rejection. In this study, we wished to determine whether corneal grafts at "high-risk" of rejection were also protected after selective SM LN removal and if so to investigate whether this improved corneal graft survival was due to induction of specific regulatory/suppressor cells or was due to immunological "ignorance".

Methods: Two sets of experiments were performed. (I) Adoptive transfer of possible regulatory splenocytes from mice with long-term accepted corneal graft after SM LN removal. (2) SM LN removal and corneal grafts in "high-risk" hosts, which had been (A) subjected to corneal trauma with vascularization or (B) allosensitized by previous corneal graft or (C) allosensitized by previous skin graft.

Results: Adoptive transfer of splenocytes from tolerant mice after SM LN removal did not enhance corneal graft survival in naive recipients $(p>0.05)$.

SM LN removal in mice with corneal vascularization enhanced corneal allograft survival compared to grafted controls with/without vascularization $(p<0.0001)$. The removal of the SM LN in mice, who had already been allosensitized by a previous corneal graft, did not statistically prolong corneal graft survival $(p>0.05)$. SM LN removal procedure did not delay rejection of corneal grafts in mice allosensitized by a previous skin transplant with the same strain combination $(p>0.05)$.

Conclusion: The results suggest that removal of the SM LN in "high-risk" mice prevents rejection by mechanisms involving immune "ignorance", since prior allosensitization prevents graft acceptance after $\mathrm{LN}$ removal. In allosensitized recipients the stronger the allosensitization (skin- vs. corneal graft-presensitization) the greater the possibility of priming for rejection at alternative draining $L N$ sites.
\end{abstract}

\section{Background}

Draining cervical lymph nodes (LN) play a critical and necessary role in allosensitization and corneal graft rejection and their complete removal results in enhanced or even indefinite graft survival in "low-risk" $[1,2]$ and prevascularized corneal grafts recipients [3]. We have previously shown that the submandibular (SM) LN is selectively involved in priming of the alloimmune response 
after corneal grafting in naive mice [2] and in recipients of a second corneal graft $[2]$, while the spleen $[1,2]$ and to a lesser extent the superficial cervical LN [2] appear to play a protective role in corneal graft rejection. The mechanism underlying prolonged graft survival after removal of the SM LN is not fully understood. One possibility is that the absence of the LN removes the lymphatic "priming" role of the draining $\mathrm{LN}$ while enhancing the protective role of the spleen via induction of regulatory T cells [4]. The tolerizing $\mathrm{T}$ cells from the spleen thus might predominate after corneal grafting and shift it to the tolerance mode. The second possibility is that LN removal simply prevents the priming of the immune response and therefore the organism is in a state of "alloantigen-ignorance". In order to determine whether prolonged corneal survival of allografts after LN removal was due to "ignorance" of priming via draining LN cells or suppression by spleen derived T regulatory cells, we have adoptively transferred splenocytes from post-LN removal tolerant mice with clear grafts to naive mice prior to corneal grafting. To further investigate these two possible mechanisms, the effect of SM LN removal in three types of "high-risk" recipients was compared.

\section{Methods \\ Mice}

Inbred female and male mice of the BALB/c $\left(\mathrm{H}^{\mathrm{d}}\right)$ and $\mathrm{C} 57 \mathrm{BL} / 10\left(\mathrm{H}^{\mathrm{b}}{ }^{\mathrm{b}}\right)$ strains 6 to 8 weeks old were obtained from the animal facility at The Institute of Molecular Genetics, Academy of Sciences, Prague. The procedures adopted conformed to the regulations of the Animal License Act (UK) and to the ARVO Statement for the use of Animals in Ophthalmic and Vision Research.

\section{Corneal grafting procedure}

The procedure was adapted from the technique described previously by She et al. [5]. Donor corneas (C57BL/10 mice, $\left.\mathrm{H}-2^{\mathrm{b}}\right) 2 \mathrm{~mm}$ in diameter were removed and placed in balanced salt solution. The recipient mice (BALB/c, H$2^{d}$ ) were anesthetized by intramuscular injection of a mixture of ketamine and xylazine diluted in saline. To dilate the pupil a combination of tropicamide $1 \%$ and phenylephrine $2.5 \%$ drops was used. The recipient right cornea was marked with a $1.5 \mathrm{~mm}$ trephine and excised using Vannas scissors after penetrating the anterior chamber with a sharp needle. Provisc ${ }^{\circledast}$ was used to maintain the anterior chamber throughout the procedure. The donor graft was sutured into the recipient bed using a running suture (11-0 Ethilon, Ethicon, UK). After grafting, antibiotic ointment (neomycin with bacitracin) was applied to the eye. The suture was not removed.

\section{Clinical evaluation of rejection}

The mice were examined every 2 to 4 days using the operating microscope. The opacity grade of the grafted cornea was used as the indicator of graft rejection [6]. The scale of opacity was zero to four, where grade 2 (vessels of the iris still distinguishable through a hazy cornea) or more was considered as graft rejection.

\section{Technique of lymph node removal}

A modified technique after Wolvers et al. [7] was used. In brief, mice were anesthetized by intramuscular injection of a mixture of ketamine and xylazine diluted in saline. The right eye was protected from drying by suturing the eyelids (the suture was removed after recovery). The skin of the neck was moisturized with chlorhexidine and shaved with a sharp razor blade. A small incision in the middle of the head-neck region was made, and with the aid of an operating microscope, the SM LN was removed bilaterally. The wound was closed with three interrupted mattress' sutures (5/0 Ethilon, Ethicon, UK) and cleaned with chlorhexidine. Seven days after LN removal corneal grafting was performed.

\section{Adoptive transfer of splenocytes}

The procedure described previously by Holan et al. [8] was used. The spleens of mice, in which the corneal graft remained clear over the period of 40 days after grafting, were removed and the splenocytes isolated and injected $\left(50 \times 10^{6}\right.$ in $0.5 \mathrm{ml}$ of PBS) i.v. into the tail vein of the $\mathrm{BALB} / \mathrm{c}$ mice. One day later, corneal grafting in these recipient mice was performed (15 mice).

\section{Preparation of "high-risk" mice}

"High-risk" recipients are mice in which graft rejection is accelerated. In our experiment, three types of "high-risk" mice were used:

\section{Group A}

Grafts in vascularized corneas. Corneal vascularization was induced in 17 mice by four interrupted stitches placed in the four quadrants of the cornea three weeks prior to corneal allografting. SM LN removal was performed in 8 of these mice 7 days prior to corneal grafting (Figure 1).

\section{Group B}

Presensitization by prior corneal grafting. A presensitizing corneal graft was performed in 11 mice and retained for a period of 3 weeks. The graft was then replaced by a second "test" corneal graft, irrespective of the rejection status of the first graft. SM LN removal was performed in 6 of these mice 7 days prior to the test graft (Figure 1).

\section{Group C}

Presensitization by prior skin grafting. A presensitizing skin graft was performed in 8 mice and retained for a period of 3 weeks. A corneal graft with the same strain combination was then performed. SM LN removal was 


\section{Group A: prevascularization Group B: corneal allografting Group C: skin allografting \\ $2 \mathrm{w} \longrightarrow+$ - SM LNR $\stackrel{1 \mathrm{w}}{\longrightarrow}$ Corneal allografting}

\section{Figure I}

Procedures performed to create a "high-risk" corneal graft recipient. Abbreviations: w - weeks, SM LNR - submandibular lymph node removal.

performed in 4 of these mice 7 days prior to corneal grafting (Figure 1).

\section{Skin grafting procedure}

The technique of skin grafting was reported previously [9]. In brief: the tail skin of C57BL/10 mice was removed and placed onto the back of anesthetized (mixture of ketamine and xylazine) BALB/c recipients and fixed by a splint around the thorax. The splint was removed 5 days later and skin rejection assessed by integrity of the donor graft.

\section{Statistical analysis}

To compare survival of corneal grafts between experimental groups, Mann Whitney U test (GraphPad InStat software) by comparing the days of onset of rejection, was used.

\section{Results}

\section{Role of spleen-derived regulatory T cells after SM LN} removal

Syngeneic splenocytes from mice, which retained fully accepted clear corneal allografts after SM LN removal [2], were isolated and adoptively transferred to naive mice. 24 hours later the recipient mice underwent corneal allografting. No difference in rejection rate was observed between mice, which had received the splenocytes compared to untreated control mice. Fourteen of 15 (93\%) mice after adoptive transfer rejected their corneal grafts within the 60 days observation period (Figure 2, p > 0.05 compared to controls).

\section{Role of immunological "ignorance" versus active immunosuppression in corneal graft survival after SM LN removal \\ Mice with prevascularized corneas}

In this group (Group A, see Methods), the animals were examined for up to 60 days post corneal grafting. Within this period, $100 \%$ of prevascularized "high-risk" recipients (9 mice) rejected their allografts in a "high-risk" manner (i.e. at an accelerated tempo of rejection) compared to the untreated grafted controls (Figure 3, Table 1). Despite the "high-risk" status of the graft, removal of SM LN delayed the rejection onset in all prevascularized recipients and even prevented rejection in 50\% (4 of 8 mice) of them (Figure 3, p $<0.0001$ compared to prevascularized controls, Table 1).

\section{Mice presensitized by a corneal grafting}

This group of animals (Group B, see Methods) was examined for 60 days after the second corneal graft procedure. $80 \%$ (four of five) of the "high-risk" recipients rejected the allografts within this period. SM LN removal protected $33 \%$ (two of six) of the second-graft-recipients from graft rejection (Figure 4). At day 15 after transplantation, 3 of 5 "high-risk" control mice had rejected while only 1 of 6 "high-risk" mice, who had SM LN removal, had rejected. This difference was not statistically significant when median grades were evaluated by day $60(\mathrm{p}>0.05$, Table $1)$.

Mice presensitized by a skin graft

SM LN removal did not influence the outcome of corneal grafting in this group (Group C, see Methods) of mice and both the "high-risk"-LN removal-group and "high-risk" controls rejected within 12 days from corneal grafting (Figure 4, p >0.05, Table 1).

\section{Discussion}

The experiments described here were designed to determine, which of two possibilities was the more probable explanation for prolonged corneal allograft survival after removal of the draining $\mathrm{LN}$ : a) protection via predominance of spleen-derived $\mathrm{T}$ regulatory cells, or $\mathrm{b}$ ) protection via "ignorance" of draining LN T inducer priming cells. In testing the first hypothesis, we asked whether tolerance, once established, was transferable by putative regulatory $\mathrm{T}$ cells to a naive recipient. Infectious tolerance as a phenomenon has been described repeatedly in other models $[8,10-12]$, in which adoptive transfer of whole splenocytes i.v. in a range 50 to $100 \times 10^{6}$, the same numbers as 


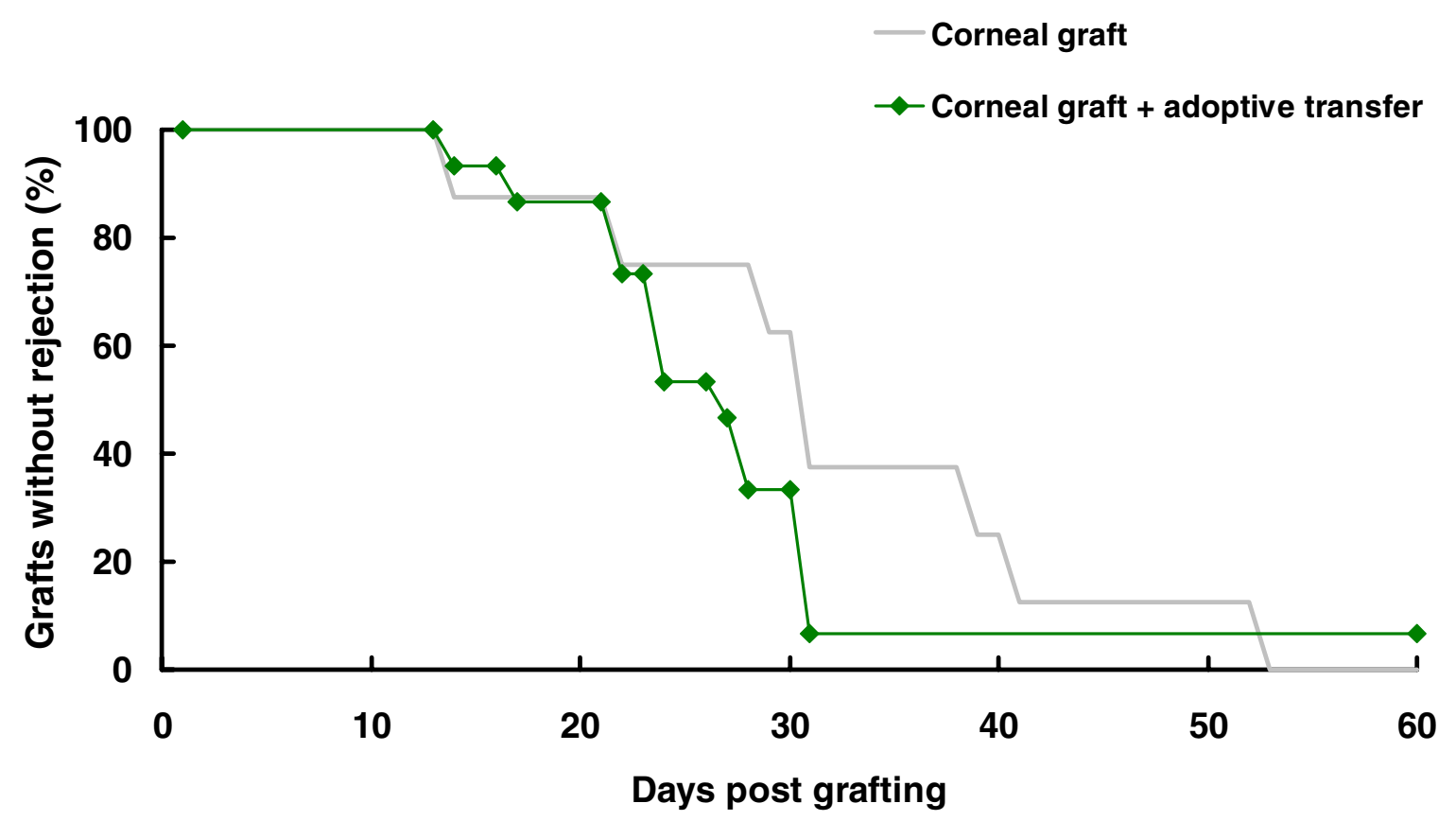

Figure 2

Adoptive transfer of splenocytes. Percentage of the grafts staying clear during the 60-day period in mice after adoptive transfer of splenocytes from mice with clear corneas after submandibular lymph node removal. Compared to controls with corneal grafting alone.

used in the present experiments, led to graft acceptance. We have therefore performed adoptive transfer of $50 \times 10^{6}$ splenocytes from mice with long-term accepted allografts after removal of the draining LN, to naive animals prior to corneal grafting, in order to follow previous established protocols. However, there was no significant difference in terms of graft acceptance between this group of animals and normal allografted controls; therefore, prolongation of corneal graft survival did not seem to be due to the induction of $\mathrm{T}$ regulatory cells. In our experiments, the spleens were removed from mice 40 days after corneal graft and the grafts were crystal clear at that time. A period of 40 days is considered long-term graft survival in mice. However, it is possible that in a very small proportion of mice rejection can start even after this period. If spleens from such mice, in which the corneal graft is clear but high levels of primed T cells had been induced in the spleen or other secondary lymphoid organs, such splenocytes would not transfer tolerance but rather sensitization.

In addressing the second possibility i.e. that loss of priming of allogeneic $\mathrm{T}$ cells is caused by immunological "ignorance" we hypothesized that we should be able to prevent rejection in recipient mice, who were at high risk of rejection without prior exposure to the antigen. In contrast, in mice previously sensitized to the antigen i.e., who were no longer naive, removal of the draining LN should make no difference to the rate of graft rejection.

Accordingly, we set up three groups of "high-risk" corneal graft recipients. An experimental model of "high-risk" corneal grafting has been reported frequently $[3,13-15]$ and 


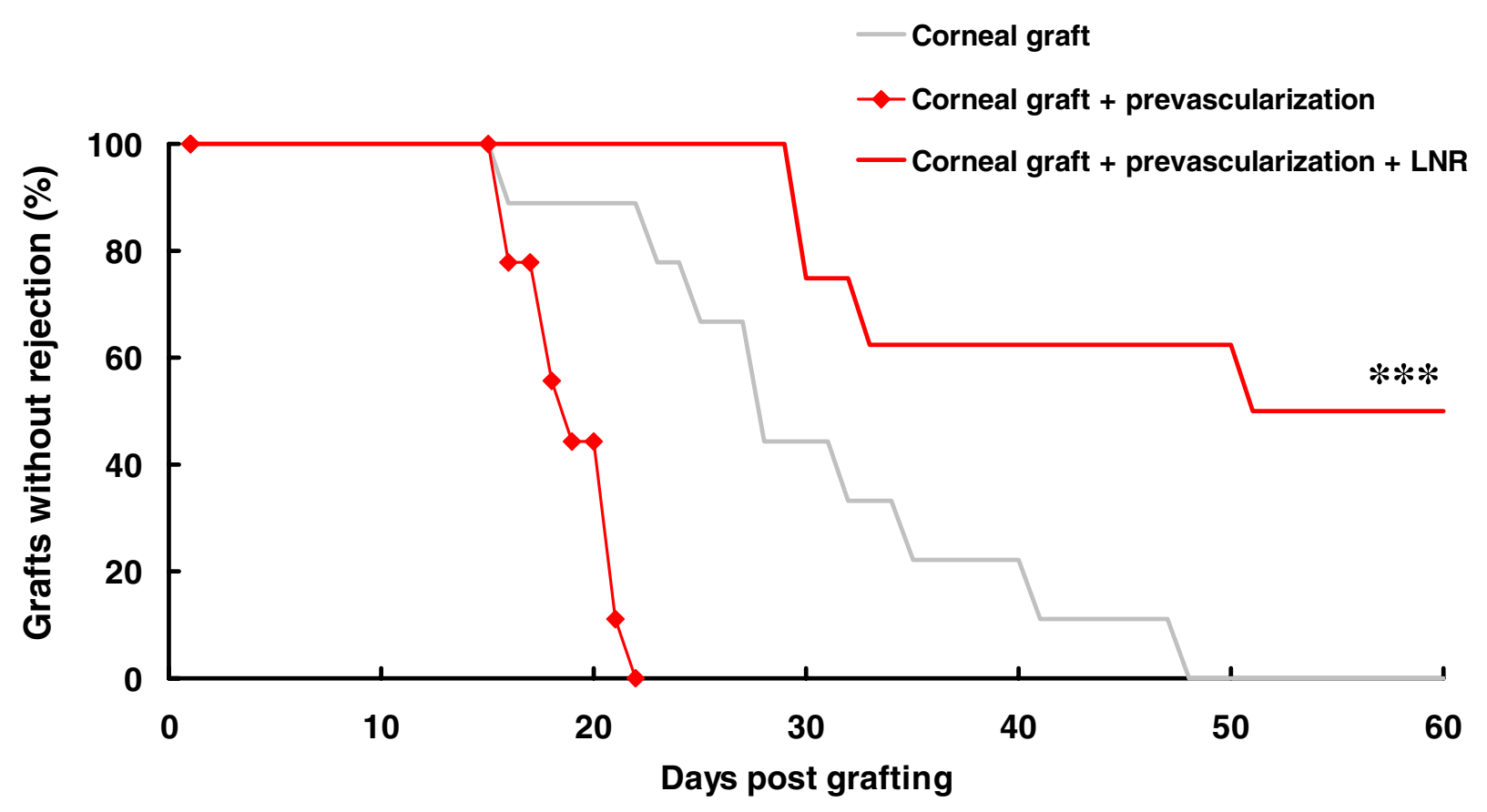

Figure 3

Corneal graft survival in prevascularized recipients. Percentage of the grafts staying clear during the 60-day period in "high-risk" mice with prevascularized corneas (Group A) with or without SM LN removal compared to controls with corneal grafting alone. *** - $\mathrm{p}<0.00 \mathrm{I}$ compared to "high-risk" controls. Abbreviations: LN - lymph node, SM - submandibular.

Table I: Median survival time in all experimental groups of mice

\begin{tabular}{lcc}
\hline Groups of mice & $\mathbf{n}$ & Median survival time (days) \\
\hline Naive mice + corneal graft & 8,9 & $31.0,28.0$ \\
Adoptive transfer of splenocytes + corneal graft & 15 & 25.5 \\
Prevascularized corneas + corneal graft & 9 & 19.0 \\
Prevascularized corneas + LNR + corneal graft & 8 & 56.0 \\
Presensitized by a corneal graft + corneal graft & 5 & 14.0 \\
Presensitized by a corneal graft + LNR + corneal graft & 6 & 21.0 \\
Presensitized by a skin graft + corneal graft & 4 & 10.0 \\
Presensitized by a skin graft + LNR + corneal graft & 5 & 8.0 \\
\hline
\end{tabular}

Abbreviations: LNR - lymph node removal, $\mathrm{n}$ - number of mice. 


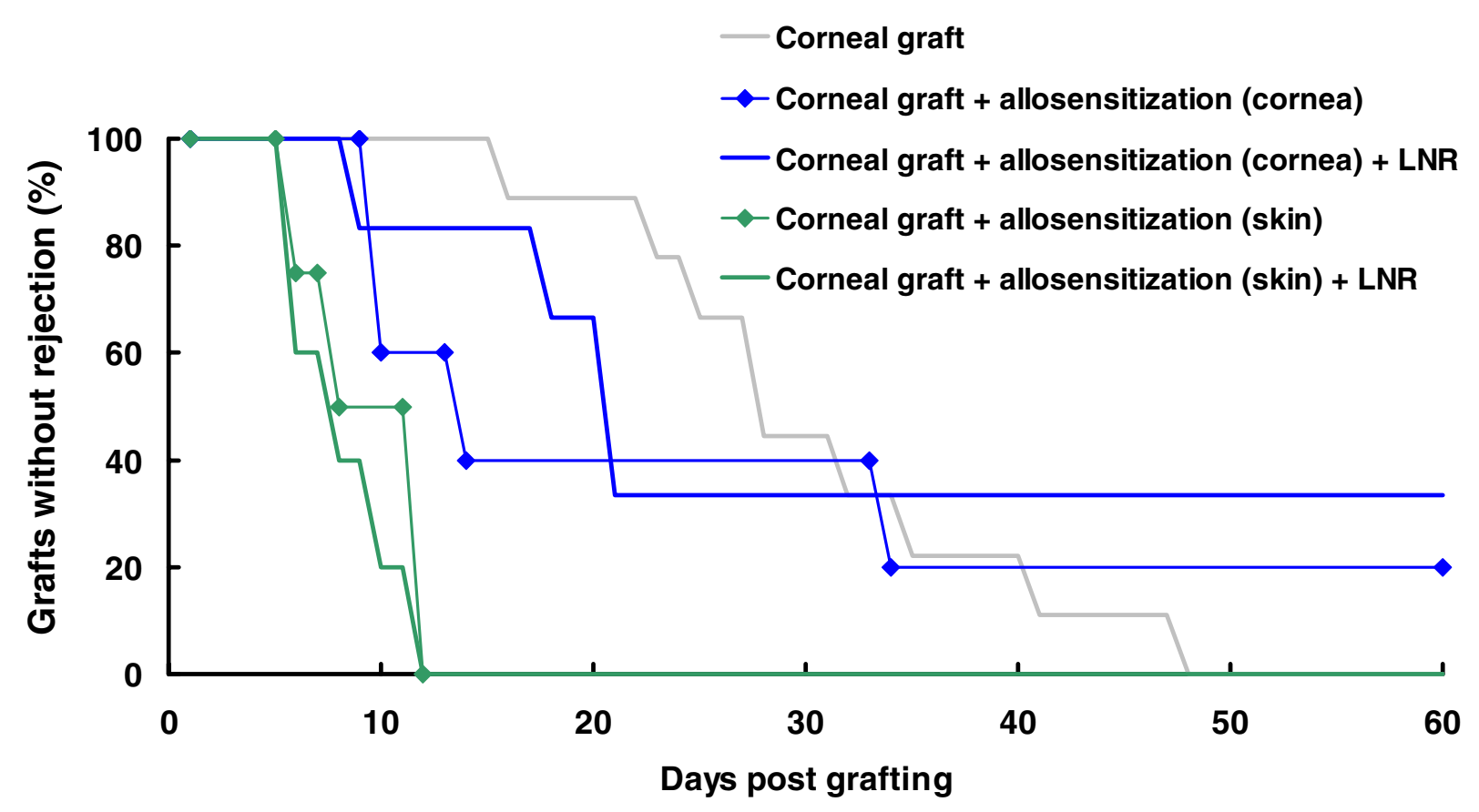

Figure 4

Corneal graft survival in allosensitized recipients. Percentage of the grafts staying clear during the 60-day period in "high-risk" mice with corneal (Group B) or skin (Group C) graft-allosensitization with of without SM LN removal compared to controls with corneal grafting alone. Abbreviations: LN - lymph node, SM - submandibular.

the higher risk of transplantation in such recipients is expressed either as the higher percentage of rejected grafts or a faster onset of the rejection process. In these models, however, there may be several reasons for the "high-risk" status. The method most commonly used in the mouse model is induced prevascularization of the recipient cornea [13-15]. This model is equivalent to human recipients with scarred, vascularized corneas for example after ocular trauma. In corneal grafting, however, several other factors increase the risk of graft rejection, such as retransplantation in a recipient with previously failed graft, ocular surface disease, infection of the eye causing scarring and vascularization, size of the graft, and others. It is believed that the key factor in regraft models is allosensitization of the recipient, which is achieved in an animal model by either previous skin [9] or corneal graft [2]. We have in our study compared the role of SM LN removal in three types of "high-risk" corneal grafts: prevascularized non-allosensitized recipients and allosensitized recipients via prior corneal or skin graft from the same mouse strain.

In animals that were prevascularized but not allosensitized, $\mathrm{LN}$ removal resulted in a significant increase in graft survival, 0 to $50 \%$ during the 60 -day observation period. In animals with previous corneal graft, LN removal had a minor but not statistically significant effect. Corneal grafts in mice after skin grafting with or without SM LN removal resulted invariably in $100 \%$ rejection by 12 days post corneal grafting. Therefore, priming of the immune system via separate regional lymphatic system, such as the skin, is not affected by the SM LN removal and sensitization to alloantigen is still possible. 
In our previous studies [2], we have shown that "sham operation", in which the skin incision without LN removal is performed, leads to the same level of corneal graft survival as in the naive untreated control group of mice. These experiments were therefore not repeated.

At present in clinical corneal graft practice, attention is paid mostly to aspects such as HLA matching and the use of immunosuppressants, which are quite broad spectrum and have significant side effects. The results of these experiments confirming the role of the draining LN in priming corneal graft rejection suggest that a more targeted or regional approach to immunosuppresion may be possible.

\section{Conclusions}

The high rate of long-term corneal graft acceptance after draining LN removal is most likely due to prevention of priming the immune system to alloantigen. In both "lowrisk" and "high-risk" corneal graft-recipients this effect is confirmed, but only if the "high-risk" status of the recipient does not involve allosensitization. However, if the recipient has already been primed by previous corneal or skin graft, the protective effect of LN removal is lost, especially with "strong" alloinducers such as skin grafting. Thus the stronger the presensitization of the recipient (skin versus corneal graft), the lesser effect of the LN removal on the final outcome of corneal grafting.

\section{Abbreviations}

LN - lymph node, LNR - lymph node removal, SM submandibular.

\section{Competing interests}

None declared.

\section{Authors' contributions}

JP carried out the corneal grafting, prevascularization of the corneas, lymph node removal and animal examination, and drafted the manuscript. VH participated in the design of the study and performed the skin grafting and adoptive transfer procedures. MF participated in the design of the study. JVF conceived of the study and participated in its design and coordination. All authors read and approved the final manuscript.

\section{Acknowledgements}

This work was performed with University of Aberdeen Development Trust, Grant IGA MZ CR NI 6019-3/2000 and Welcome Trust Grant 06/347/Z/00/Z.

\section{References}

I. Yamagami S, Dana MR: The critical role of lymph nodes in corneal alloimmunization and graft rejection. Invest Ophthalmol Vis Sci 200I, 42: 1293-1298.
2. Plskova J, Duncan L, Holan V, Filipec M, Kraal G, Forrester JV: The immune response to corneal allograft requires a site-specific draining lymph node. Transplantation 2002, 73:210-215.

3. Yamagami S, Dana MR, Tsuru T: Draining lymph nodes play an essential role in alloimmunity generated in response to highrisk corneal transplantation. Cornea 2002, 21:405-409.

4. Faunce ED, Stein-Streilein J: NKT cell-derived RANTES recruits APCs and CD8+ cells to the spleen during the generation of regulatory T cells in tolerance. J Immunol 2002, 169:3I-38.

5. She S-C, Steahly LP, Moticka EJ: A method for performing fullthickness, orthotopic, penetrating keratoplasty in the mouse. Ophthalmic Surg 1990, $21: 781-785$.

6. Plskova J, Kuffova L, Holan V, Filipec M, Forrester JV: Evaluation of corneal graft rejection in a mouse model. Br J Ophthalmol 2002, 86:108-II3.

7. Wolvers DA, Coenen-de Roo CJ, Mebius RE, van der Cammen MJ, Tirion F, Miltenburg AM, Kraal G: Intranasally induced immunological tolerance is determined by characteristics of the draining lymph nodes: studies with OVA and human cartilage gp-39. J Immunol 1999, 162:1994-1998.

8. Holan V, Hasek M, Chutna J, Holoubkova I: Mechanisms of tolerance of the la antigen disparate skin allografts. Folia Biol (Praha) 1982, 28:395-408.

9. Haskova Z, Filipec M, Holan V: The role of major and minor histocompatibility antigens in orthotopic corneal transplantation in mice. Folia Biol (Praha) 1996, 42:105- III.

10. Hasek M, Holan V, Chutna J: Comparison of neonatally and adoptively induced transplantation tolerance in mice. Folic Biol (Praha) 1980, 26: 167-I75.

II. Kataoka M, Margenthaler JA, Ku G, Flye MW: Development of infectious tolerance after donor-specific transfusion and rat heart transplantation. J Immunol 2003, I 7 I:204-2II.

12. Kataoka M, Margenthaler JA, Ku G, Eilers M, Flye MW: "Infectious tolerance" develops after the spontaneous acceptance of Lewis-to-Dark Agouti rat liver transplants. Surgery 2003, 134:227-234.

13. Sano Y, Ksander BR, Streilein JW: Fate of orthotopic corneal allografts in eyes that cannot support anterior chamber-associated immune deviation induction. Invest Ophthalmol Vis Sci 1995 , 36:2176-2185.

14. Sano Y, Ksander BR, Streilein JW: Murine orthotopic corneal transplantation in high-risk eyes. Rejection is dictated primarily by weak rather than strong alloantigens. Invest Ophthalmol Vis Sci 1997, 38: I I30-1 I38.

I5. Dana MR, Yamada J, Streilein JW: Topical interleukin I receptor antagonist promotes corneal transplant survival. Transplantation 1997, 63:1501-1507.

\section{Pre-publication history}

The pre-publication history for this paper can be accessed here:

http://www.biomedcentral.com/1471-2415/4/3/prepub

Publish with Bio Med Central and every scientist can read your work free of charge

"BioMed Central will be the most significant development for disseminating the results of biomedical research in our lifetime. "

Sir Paul Nurse, Cancer Research UK

Your research papers will be:

- available free of charge to the entire biomedical community

- peer reviewed and published immediately upon acceptance

- cited in PubMed and archived on PubMed Central

- yours - you keep the copyright

Submit your manuscript here:

http://www.biomedcentral.com/info/publishing_adv.asp
BioMedcentral 